\title{
Ramazan Ayında Oruç Tutan Diyabetli Bireylerde Diyabetin Yönetimi
}

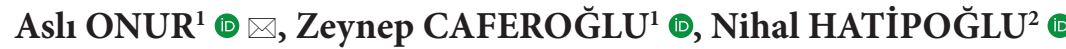 \\ ${ }^{1}$ Erciyes Üniversitesi, Sağlık Bilimleri Fakültesi, Beslenme ve Diyetetik Bölümü, Kayseri, Türkiye \\ ${ }^{2}$ Erciyes Üniversitesi, Tıp Fakültesi, Çocuk Sağlığı ve Hastalıkları Anabilim Dalı, Kayseri, Türkiye \\ Bu makaleye yapılacak atıf: Onur A, Caferoğlu Z, Hatipoğlu N. Ramazan Ayında Oruç Tutan Diyabetli Bireylerde Diyabetin Yönetimi. Turk J Diab Obes 2021 ;: $59-67$.
}

ÖZ

Diabetes mellitus (DM) kronik metabolik bir hastalık olduğu ve oruç sırasında hipoglisemi, hiperglisemi, dehidratasyon ve koagulasyon gibi riskler taşıdığından Ramazan orucu için riskli bir durum olarak kabul edilir. Ramazan ayı boyunca Müslümanlar, şafaktan gün batımına kadar geçen süre boyunca yiyecekten, içecekten, sigaradan ve cinsel ilişkiden uzak dururlar. Ramazan ayı 29-30 gün sürmekte ve oruç tutulan süre coğrafi konuma göre 10 ila 20 saate kadar uzun bir zaman dilimini kapsamaktadır. Oruç tutmak için şart, sağlıklı olmak ve kronik hastalı̆̆a sahip olmamaktır. Ancak, dini zorunluluk olduğu ve manevi fayda sağlayacağı düşüncesiyle kronik hastalı̆̆ı olan çoğu birey de oruç tutmayı istemektedir. Ramazan ayında oruç sırasında hipoglisemi korkusu da yaygın bir sorundur. Bununla birlikte, klinik uygulamada DM'li bireylerin çoğu oruç tutmayı tercih etmektedir. Bu nedenle sağlı uzmanlarının çeşitli risklere karşı DM'li bireyleri koruması, hipoglisemik ve hiperglisemik olayları önlemek için bu özel durumlara özgü eğitim vermesi zorunluluğu kaçınılmazdır. Bu derleme, sağlık uzmanlarının Ramazan ayında oruç tutmayı planlayan tip 1 ve tip 2 DM'li yetişkin bireylere kılavuzların önerileri doğrultusunda risk sınıflandırması, eğitim, farmakoterapi ve kan şekeri takibi, ilaç ve doz ayarlaması gibi önerilerde bulunabilmek için hazırlanmıştır.

Anahtar Sözcükler: Diabetes mellitus, Glisemik kontrol, Kan şekeri takibi, Farmakoterapi, Oruç, Ramazan, Hipoglisemi, Koagülasyon bozukluğu

\section{Management of Diabetes in Individuals with Diabetes who are Fasting During Ramadan}

\begin{abstract}
Fasting, which is important in many religions, is also one of the five pillars of Islam. During the month of Ramadan, Muslims do not eat, drink, smoke and abstain from sexual activity from dawn to sunset. The month of Ramadan lasts for 29-30 days and the fasting period ranges from 10 to 20 hours depending on geographic location. The condition for fasting is to be healthy and having no chronic illness. However, with the thought that it is a religious obligation and will provide spiritual benefit, most individuals with chronic diseases also want to fast. Diabetes mellitus (DM) is considered a high risk condition for fasting in Ramadan, as it is a chronic metabolic disease and carries risks such as hypoglycemia, hyperglycemia, dehydration and coagulopathy during fasting. Fear of hypoglycemia is a common problem during fasting on holy month Ramadan. However, in clinical practice, most individuals with DM prefer to fast. Therefore, healthcare professionals must provide education sessions to protect individuals with DM against various risks and help prevent hypoglycemic as well as hyperglycemic events. This review has been prepared for health professionals in order to make recommendations such as dose adjustments, risk stratification, diabetes patient education, updating pharmacotherapy and how to make blood glucose monitoring according with the recommendations of the guidelines for adults with type 1 and type 2 DM who plan to fast during Ramadan.
\end{abstract}

Keywords: Diabetes mellitus, Glycemic control, Blood glucose monitoring, Pharmacotherapy, Fasting, Ramadan, Hypoglycemia, Coagulopathy

ORCID: Aslı Onur / 0000-0002-3099-8479, Zeynep Caferoğlu / 0000-0002-7226-5636, Nihal Hatipoğlu / 0000-0002-0991-6539 


\section{GİRIS}

Oruç, ortalama günde yaklaşık 12 saat süre ile 4 hafta boyunca yiyecek, içecek veya her ikisinin (mutlak) gönüllü olarak bırakılması olarak tanımlanabilir. Oruç tutmak; sadece İslamiyet'te değil; Hıristiyanlık, Yahudilik ve Hinduizm dâhil olmak üzere farklı dini disiplinlerde yaygın bir uygulamadır (1). Ramazan orucu ise bir buçuk milyardan fazla insanın uyguladığı İslam'ın beş şartından biridir ve Ramazan ayında oruç tutmak tüm sağlıklı, aklı başında Müslümanlar için zorunlu bir görevdir (dini bir vecibedir). Müslümanlar şafaktan gün batımına kadar yiyecek, içecek, oral ilaçlar, sigara ve cinsel ilişkiden uzak durmaktadır (2).

Ramazan orucu, İslami takvim olan ay yılını esas aldığı için her yıl bir önceki yıla göre 10 ila 11 gün önce başlar. Bu nedenle şafaktan gün batımına kadar olan oruç süresi kışları kısa bir günden yazları uzun bir güne kadar önemli ölçüde değişebilir (3). Uyku zamanlarında ve şafaktan önce tüketilen ögünlerde değişimler gözlenmektedir. Mevsime ve ülkenin coğrafi konumuna bağlı olarak oruç süreleri 9 ila 20 saat arasında değişmektedir (4).

Oruç tutarken uzun saatler aç kalmanın yanında geleneksel olan sahur ve iftar yemekleri normal yemeklerden farklıdır ve genellikle yüksek glisemik indekse sahip karbonhidrat içeriği yüksek besinler dikkati çekmektedir. Bireyler özellikle iftarda oruçlarını açtıklarında normalden daha büyük porsiyonlar tüketme eğilimindedir (3). Bu nedenle, Ramazan orucu nokturnal ve kısa sürede yüksek enerjili besinlerle beslenmeyi içeren bir açlık türüdür (1).

Oruç için şart sağlıklı olmaktır; ancak kronik hastalığı olan birçok kişi riskleri görmezden gelir ve tıbbi koşullarına rağmen oruç tutmayı tercih eder (3).

Müslümanlar Dünya nüfusunun \%24’ünü (1.8 milyar birey) oluşturmakta ve önemli bir kısmı da oruç tutmaktadır (3). Diyabet ve Ramazan Epidemiyolojisi (Results of the Epidemiology of Diabetes and Ramadan 1422/2001, EPIDIAR) çalışmasında 100 milyondan fazla Müslümanın Ramazan ayında oruç tuttuğu ve bu oranın tip 1 DM'li bireylerde \%43, tip 2 DM'li bireylerde ise \%79 olduğu gösterilmiştir (5). Bunun yanında, Müslüman nüfusu yüksek olan bazı bölgelerde önümüzdeki 25 yıl içinde DM’li birey sayısının iki kattan fazla artacağı beklenmektedir (6).

Öğünler arasındaki uzun boşluk; iştahı, besine karşı hormonal tepkileri, enerji ve glukoz metabolizmasinı etkilemektedir (4). Diyabetik bireyler oruç tutarken hipoglisemi ve hiperglisemi, diyabetik ketoasidoz, hiperosmolar hiperglisemi, dehidrasyon, hipotansiyon ve tromboz gibi risklerle karşı karşıyadır (6). EPIDIAR çalışmasında, Ramazan ayında hastaneye yatmayı gerektiren şiddetli hipoglisemi insidansının tip 1ve tip 2 DM'li bireylerde sırasiyla 4.7 ve 7.5 kat ve ketoasidozu olan/olmayan şiddetli hiperglisemi insidansinın tip 1 ve tip 2 DM'li bireylerde sirasiyla 3 ve 4.4 kat artışa neden olduğu saptanmıştır (5). Bunlardan yola çıkarak, DM'li bireylerde oruç zamanlarında hipoglisemi ve hiperglisemi riskleri en önemli sorunlar olarak karşımıza çıkar (7).

Ramazan ayında DM'li bireylerde oruç tutma küresel tıbbi bir sorundur ve bu konuda sağlık uzmanları danışmanlık yapmakta zorlanmaktadır. Hangi hastanın oruç için uygun olduğu, doğru kan şekeri takibi (KŞT), antihiperglisemik ajanların ayarlanması hakkında bilgi yetersizliği yaşanmaktadır. Bu nedenle, Uluslararası Diyabet Federasyonu (International Diabetes Federation, IDF) ve Diyabet ve Ramazan Uluslararası İttifak Kuralları (The Diabetes and Ramadan International Alliance, DAR), DM'li bireyleri çeşitli hastalık özelliklerine ve kullanılan antihiperglisemik ajanlara göre risk gruplarına ayırmakta, Amerikan Diyabet Derneği (American Diabetes Association, ADA) ve Avrupa Diyabet Çalışma Derneği (European Association for the Study of Diabetes, EASD) önerileri ile yapılandırılmış eğitim ve Ramazan öncesi danışmanlıkla, DM'li hastaların başarılı yönetimi için protokoller geliştirmektedirler $(6,8,9)$.

Ramazan ayından önce DM'li bireylere DM yönetimi hakkında verilen eğitim programları ile glisemik kontroller sağlanarak oruç tutulabileceği gösterilmiştir (7). Komplikasyon riskini değerlendirmek amacıyla yapılan bir çalışmada, yüksek ve çok yüksek risk grubunda yer alan DM'li bireylere oruç öncesi eğitim verilmiş ve Ramazan öncesi bireylerin \%5.4'ünün, Ramazan ayında \%8.8'inin hipoglisemi atağı geçirdiği belirlenmiştir (9). EPIDIAR çalışmasında bireylerin oruçluyken 6 kat daha fazla hipoglisemi yaşadığı saptanmıştır (5). Brunei'de Ramazan ayında oruç tutan DM'li bireylerle yapılan ilk epidemiyolojik çalışmada, katılımcıların yalnızca \%49.1’i sağlık uzmanlarına Ramazan ayından önce danışmış, özellikle Ramazan ayından önce ve sırasında DM eğitimi alan bireylerde hipoglisemik risklerin en aza indiği ve DM komplikasyonlarının sıklığının azaldığ ulaşılmıştır (7). Yapılan gözlemsel kesitsel bir çalışmada ise Ramazan ayından önce 2 gün boyunca üç ana öğünün öncesi ve sonrasında, Ramazan ayında iftardan önce ve sahurdan iki saat sonra tip 2 DM'li bireylerin kan şekeri (KŞ) izlenmiştir. Ayrıca bireylere Ramazan öncesinde glukoz izlemi konusunda eğitim verilmiş ve diyet danışmanlığı ile birlikte ilaç-doz ayarlaması yapılmıştır. Ramazan ayından iki gün önce ve Ramazan ayında KŞ seviyeleri ortalama 150$187 \mathrm{mg} / \mathrm{dL}$ saptanmış ve aşırı dalgalanma gözlenmemiştir. Ramazan ayında DM'li bireylere uygun eğitim, diyet danışmanlığı ve ilaç-doz ayarlaması yapıldığında bireylerin yaşamını tehdit eden herhangi bir komplikasyon oluşmadığı sonucuna varılmıştır (10). Ramazan ayında DM'li bireylerde yapılan eğitimler riskleri azaltmaktadır (11). 
Diyabetli bireylerin oruç tutması konusunda önemli hususlar, takip ve tedavi şartları IDF-DAR ve ADA/EASD kılavuzları doğrultusunda aşağıda sıralanmıştır.

\section{RAMAZAN AYINDA ÖNCE DİABETES MELLITTUSUN DEĞERLENDİIILMESİ}

\section{a. Risk Gruplarının Belirlenmesi}

Ramazan öncesi DM eğitiminde, DM'li bireyleri bilinçlendirmeye odaklanılmaktadır. Takiplerde nelere dikkat edileceği ve hangi durumlarda oruca devam edilmemesi gerektiği eğitimi ile komplikasyonlar azalır (12). Oruç tutmak isteyenlerde kararlı glisemik kontrol için oruç başlamadan 1 ila 3 ay önce kişiselleştirilmiş bir değerlendirme yapılmalıdır.
Değerlendirmede ilk olarak bireyin risk sinıflandırmasının uygunluğu kontrol edilmelidir (Tablo 1) $(6,8)$.

Daha önceki oruç sırasında yaşanan deneyimler gözden geçirilmeli ve kişiselleştirilmiş bir tedavi planı oluşturulmalıdır. Ramazan ayında, antihiperglisemik ajanların ayarlanması, öğünler, fiziksel aktivite durumu, KŞT sıklığı ve durumunun hastayı tıbbi açıdan nasıl etkileyeceği tartışılmalıdır. Yüksek risk sınıflamasında olmasına rağmen oruç tutmak isteyen bireylerde sağlık ekibi ile birlikte daha yakın KŞT yapılmalı (klinikte, sanal olarak veya telefonda) ve duruma göre tedavide sık düzenlenme yapmalıdır. Risk sınıfındaki kişilere, Ramazan ayında herhangi bir hipoglisemi veya semptomatik hiperglisemi olayı yaşarlarsa, oruçlarını bozmaları ve derhal tıbbi yardım almaları tavsiye edilmelidir (3).

Tablo 1: Ramazan ayında oruç tutmak isteyen DM’li bireyler için risk sınıflandırması (6)

\begin{tabular}{|c|c|c|}
\hline Risk Grupları & $\begin{array}{c}\text { Risk Faktörleri } \\
\text { Aşağıdakilerden bir ya da daha fazlası varsa }\end{array}$ & Öneri \\
\hline Çok Yüksek Risk & 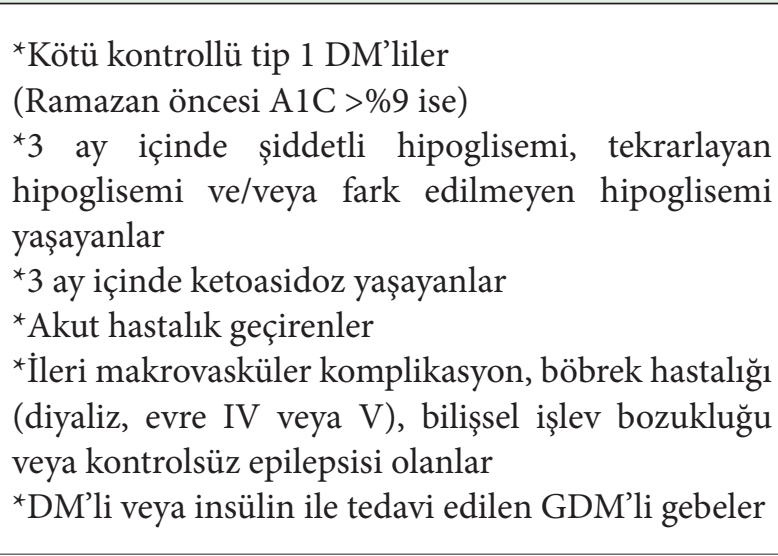 & $\begin{array}{l}\text { Kesinlikle Oruç Tutmamalıdır } \\
\text { Hastalar oruç tutmakta ısrar ederse: } \\
{ }^{*} \text { Ramazan öncesi yapılandırılmış eğitim } \\
\text { almalı ve bunu nitelikli bir diyabet ekibi takip } \\
\text { etmeli } \\
{ }^{\star} \text { Kan şekerini düzenli olarak kontrol edilmeli } \\
{ }^{*} \text { İlaç dozu önerilere göre ayarlanmalı } \\
{ }^{\star} \text { Hipo / hiperglisemi durumunda oruç } \\
\text { bozulmalı } \\
{ }^{*} \text { Sı hipo/hiperglisemi veya diğer ilgili tıbbi } \\
\text { durumların kötüleşmesi durumunda oruç } \\
\text { tutma bırakılmalı }\end{array}$ \\
\hline Yüksek Risk & 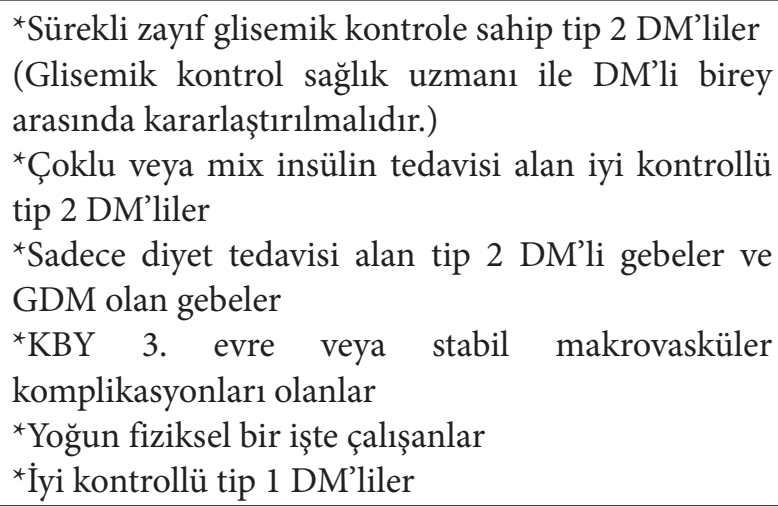 & Oruç Tutmayabilir \\
\hline Orta/Düişük Risk & $\begin{array}{l}\text { *Iyi kontrol edilen DM } \\
\text { *Sağlıklı kişilerde yaşam tarzı ile veya metformin, } \\
\text { akarboz, inkretin tedavileri (DPP-4 inhibitörleri } \\
\text { veya GLP-1 RA), ikinci nesil SÜ, SGLT2i, TZD veya } \\
\text { bazal insülin ile tedavi edilen bireyler }\end{array}$ & $\begin{array}{l}\text { Tibbi Danışmanlıkla Oruç Tutabilir } \\
\text { Oruç tutan bireyler: } \\
\text { ^Ramazan öncesi yapılandırılmış eğitim } \\
\text { almalı } \\
{ }^{\star} \text { Kan şekerini düzenli olarak kontrol edilmeli } \\
{ }^{\star} \text { İlaç dozu önerilere göre ayarlanmalı }\end{array}$ \\
\hline
\end{tabular}

DM: Diabetes mellitus, DPP-4: Dipeptidilpeptidaz-4, GDM: Gestasyonel diabetes mellitus, GLP-1 RA: Glukagon benzeri peptit-1 reseptör agonisti, KBY: Kronik böbrek yetmezliği, SGLT2i: Sodyum-glukoz yardımcı taşıyıcı-2 inhibitörleri, SÜ: Sülfonilüre, TZD: Tiazolidindion. 


\section{b. Diabetes Mellitus Yönetimi}

Ramazan öncesi diyet eğitiminde amaç, orucun olası riskleri hakkında bilgi vermek ve bireylerin davranışları hakkında bilinçli karar vermesini sağlamak olmalıdır (11). Yapılan retrospektif bir çalışmada, DM eğitimi almayan tip 2 DM'li bireylerde Ramazan ayında hipoglisemi ve ağırlık artışının olduğu, eğitim alanlarda ise hipoglisemi oranında yaklaşık \%50 azalma gözlendiği ve 0.7 kg ağırlık kaybı yaşandığı bulunmuştur (13).

Ramazan odaklı DM eğitim programı; din adamı, endokrinolog, diyabet uzmanı hemşire, fizyoterapist ve diyetisyenin yer aldığı bir komisyon tarafından düzenlenmelidir (14). Diyabet yönetiminde eğitim programının yanı sıra endişeleri gözden geçirmek ve sonraki oruçlara bir strateji belirlemeye yardımcı olmak için Ramazan sonrası sağlık bakım ziyareti düşünülmelidir (3).

\section{c. Genel Farmakoterapi Önerileri}

Ramazan başlangıcından önce antihiperglisemik ajan değişikliği kararının verilmesi, oruç tutarken hipoglisemi ve/ veya tolere edilebilirlik açısından sorun yaratabilmektedir. $\mathrm{Bu}$ durumda ajan değişikliği ve doz ayarlamaları bu gibi risklerin önüne geçebilmeye yönelik yapılmalıdır. ADA/ EASD 2018 önerileri ve son güncellemesi, aterosklerotik kardiyovasküler hastalık, kalp yetmezliği ve kronik böbrek hastalığının varlığını veya yokluğunu ajan seçiminde önemli bir etken olarak görmektedir (8).

Aşağıda IDF-DAR kılavuzlarına göre Ramazan ayında DM'li bireylerin kullandığı antihiperglisemik ajanlarla ilgili öneriler yer almaktadır;

- Ramazan'dan önce metformin, glukagon benzeri peptit-1 reseptör agonisti (GLP-1 RA), insülin sekretagogları veya sodyum-glukoz kotransporter-2 inhibitörleri (SGLT-2i) vb. alan tip 2 DM'li bireyler; kusma, diyare ve ortostaz semptomlarının herhangi birinin gelişmesi durumunda acil tıbbi yardım almalıdır (6).

- Düşük hipoglisemi veya ortostaz riskine sahip olan ajanlar [metformin, dipeptidil-peptidaz-4 inhibitörleri (DPP-4i), alfa-glukosidaz inhibitörleri ve tiazolidindionlar (TZD)] Ramazan ayında güvenle kullanılabilir (6).

- İnsülin sekretagogları, özellikle hipoglisemi riski yüksek olan bireylerde Ramazan süresince hipoglisemi riski daha düşük olan antihiperglisemik ajanlarla değiştirilmelidir (6). Farklı bir sınıfa geçmek mümkün değilse, hipoglisemi riskini azaltmak için daha düşük hipoglisemi riskine sahip insülin sekretagogları (repaglinid gibi) kullanılmalıdır $(6,15)$.
- Repaglinid (insülin sekretagog) dozu Ramazan ayında yemek zamanlarında ve miktarındaki değişikliklere göre ayarlanmalıdır (6).

- GLP-1 RA'lar düşük hipoglisemi oranları $(16,17)$ ile glisemik kontrolü sürdürmek için Ramazan'da devam edilebilir, ancak olası olumsuz gastrointestinal etkilerinden dolayı Ramazan'dan önceki 4 hafta içinde başlatılmamalıdır (6). Ramazan ayında olumsuz gastrointestinal etkiler ortaya çıkarsa, bu sınıfın dozunun azaltılması veya geçici olarak kesilmesi düşünülmelidir (6).

- SGLT-2i'ye, düşük hipoglisemi riskinden dolayı ve glisemik kontrolü sürdürmek için Ramazan ayında devam edebilir (6).

- Ramazan'da kusma, diyare veya ortostaz gelişen tip 2 DM'li bireylerde derhal oruç bozulmalı, bazı antihiperglisemik ilaçlar alınarak (metformin, sekretagoglar, GLP-1 RA, SGLT-2i) KŞT ve acil tıbbi yardım yapılmalıdır (6).

Premix veya orta etkili NPH insülin ile tedavi edilen bireylerde, oruç süresi 15 saati aştığında ve sahur ve iftar öğünleri arasındaki zaman farkı 8 saatten kısa olduğunda hipoglisemi riski daha yüksek olabilir. Sonuç olarak, Ramazan ayında tip 2 DM'li bireyler için optimal insülin rejimi veya tipi ile ilgili mevcut sınırlı verilere rağmen, küçük çalışma sonuçlar1, tedavinin bireyselleştiği ve modifiye edildiği sürece insülin tedavisi ile oruç tutmanın güvenli olabileceğini düşündürmektedir $(3,18)$.

\section{RAMAZAN AYINDA DİABETES MELLİTUSUN YÖNETIMI}

\section{a. Tip 2 Diabetes Mellitus}

\section{a.i. İnsülin Dışı Farmakoterapi Önerileri}

Ramazan ayında insülin dışı farmakoterapi alan DM'li bireylerin kullandığı antihiperglisemik ajanlar ve Ramazan ayındaki etkileri ve öneriler aşağıda belirtilmiştir;

- Alfa-glikoz inhibitörleri, Asya ülkelerinde yaygın olarak kullanılmasına rağmen bu ilaç sınıfının hafif $\mathrm{HbAlc}$ düşürücü etkinliği ve olumsuz gastrointestinal etkileri bulunmaktadır $(19,20)$. Gastrointestinal açıdan kabul edilebilirse ve her iki ögünle birlikte alınması gerekiyorsa bu ilaç sınıfına Ramazan ayında devam edilmesi güvenlidir (6).

- Biguanidlerlerden olan metformin, Ramazan ayında tip 2 DM tedavisinde ilk sırada yer almaktadır. Düşük hipoglisemi riskinden dolayı $(21,22)$, Ramazan ayında metformin için güvenlik çalışması yapılmamıştır. Gastrointestinal intoleransı en aza indirmek için oruç tutarken metforminin iftar ve sahurda alınması idealdir. Alternatif olarak bu ilacın etkisinin uzatılmış versiyonları, iftarda günde bir kez alınabilir (6). 
- DPP-4i'lerinin kullanımı; düşük hipoglisemi riski, iyi tolere edilebilir olması ve KŞ seviyelerini düşürme yeteneği $(23,24)$ nedeniyle artmıştır. Bu ajanlar sülfonilürelerle (SÜ) karşılaştırıldığında, Ramazan ayında semptomatik hipoglisemide önemli bir azalma sağlamıştır (25). Ramazan ayı boyunca hafif bir sahur yapan bireyler ve ilaçlarını sadece iftarla almayı tercih edenler için DPP-4i ile metforminin sabit doz kombinasyonu tercih edilebilir (6).

- GLP-1 RA'lar, güçlü HbA1c indirgeme ve düşük hipoglisemi riskine ek olarak doyma merkezi ve ağırlık kaybı üzerinde etkilidir (6). Liraglutid, SÜ’lere kıyasla glisemik kontrolde önemli bir iyileşmeye, semptomatik hipoglisemide azalmaya ve ağırlık kaybına yol açmaktadır $(16,17)$. Bulant1 ve gastrointestinal sistemde rahatsızlık oluşturabilmesi nedeniyle Ramazan'dan önceki 4 hafta boyunca başlatılmamalıdır. Ancak daha önce başlatılmışsa ve iyi tolere edilirse Ramazan boyunca devam ettirilebilir. Daha kısa etkili GLP-1 RA'lar (eksenatid ve lixisenatid gibi) yemeklerden önce alınmalıdır. Daha uzun etkili ajanlar ise her zaman alınabilir (6).

- İnsülin sekretagogları, Ramazan ayında hipoglisemi riskini \%20 arttırır (26). Ancak hipoglisemi riski tüm insülin sekretagoglarında eşit olarak görülmez. Hem gliklazid hem de repaglinid Ramazan sırasında hipoglisemi için nispeten daha düşük risk göstermektedir $(15,26)$. Hipoglisemi riski nedeniyle sekretagoglar Ramazan'dan önce, tercihen hipoglisemi riskini artırmayan başka bir antihiperglisemik ajan sınıfıyla değiştirilmelidir. İnsülin sekretagoglarına devam edilecekse, gliklazide devam edilmesi ancak gliburidin kesilmesi veya sadece iftardan sonra daha kısa etkili bir sekretagog alınması ve risk azaltma stratejileri hakkında danıșmanlık tavsiye edilmektedir (6).

- SGLT-2i'ler, ozmotik diürez ve natriürez nedeniyle Ramazan'da, özellikle uzun yaz oruçlarında volüm azalmasına neden olabilmektedir. Sülfonilürelerle karşılaştırıldığında volüm azalması semptomlarda daha az artışa neden olsa da hipoglisemi ve diyabetik ketoasidozda da artışa neden olabilmektedir (27). Bununla birlikte, klinik kardiyovasküler hastalık öyküsü olan bireylerde bu ilaç sinıfı azaltılırken veya bekletilirken dikkatli olunmalıdır. Çünkü yapılacak bu müdahale, kalp yetmezliğinin alevlenmesine veya bu ajanların kardiyoprotektif yararının kesintiye uğramasına neden olma potansiyeline sahiptir (28). Bu tür yüksek riskli bireyler Ramazan ayında ortostaz veya kalp yetmezliği belirtileriyle semptomatik hâle gelirse, otomatik olarak çok yüksek riskli grupta s1nıflandırılmalı ve oruç tutmaktan vazgeçirilmelidir (6).
Buna karşın gözlemsel çalışmalar bu grup ilaç kullananların çoğunda ciddi bir problemle karşılaşmamışlardır.

- Thiazolinedion (TZD) kullanan bireyler, Ramazan ayında bu ajanı almaya devam edebilirler (29). Bu sınıfın maksimum glukoz düşürücü etkisi yaklaşık 1 ay sürdüğü için Ramazan'da TZD'leri değiştirmeden veya başlatmadan önce bu zaman çizelgesi dikkate alınmalıdır. Ramazan ayında TZD'lerde ayarlama yapmaya gerek yoktur ve dozlar iftar veya sahur ile alınabilir (6).

- Sülfonilüreler yaygın bulunabilirliği nedeniyle çok fazla kullanılmaktadır. Ancak Ramazan ayında büyük endişe duyulan hipoglisemi riskini artırdığı bilinmektedir (26). Yeni nesil SÜ’ler (gliklazid, glimepirid, glipizid), eski ve daha uzun etkili ajanlara (glibenklamid gibi) kıyasla daha düşük hipoglisemi riskine sahiptir $(6,8,30)$. Yüksek hipoglisemi riski olan bireylerde SÜ dozunun değiştirilmesi, durdurulması veya azaltılması önerilmektedir $(6,8)$.

\section{a.ii. İnsülin tedavisi önerileri}

Ramazan ayında bu tedavinin etkinliği ve güvenliği; hasta eğitimi, diyet ve aktivite, doz titrasyonu, zamanlama (sahur ve iftar) ve kullanılan insülin türü de dahil pek çok faktöre bağlıdır. Enjekte edilebilir tedavi gerektiren hastaların, tercihen Ramazan başlamadan en az 4 hafta önce stabil enjekte edilebilir tedaviye uyumu çok önemlidir (8).

Ramazan'dan hemen önce veya Ramazan'da insülin başlanmasına ihtiyaç duyan tip 2 DM'li yetişkinlerde, hipoglisemi riskini azaltmak için Ramazan'da orta etkili bazal veya premix insülin seçenekleri veya bazal, uzun etkili analog insülin (detemir, glargin) veya ultra uzun analog insülin (degludec, glargine U300) tercih edilebilir. Ramazan ayında farklı insülin rejimlerinde önerilen değişiklikler aşağıda verilmiştir (6).

- Önceden orta etkili insülin kullanan (NPH, premix) bireylerde, hipoglisemi riskini azaltmak için Ramazan'dan 1 ila 3 ay önce uzun etkili veya ultra uzun etkili bazal insülin analoğuna geçilmelidir. Regüler insülinler (U500 formülasyonu), orta etkili insülinlerde olduğu gibi Ramazan öncesi alternatif bir insülin tedavisi ile değiştirilmelidir. Premix veya self-mix insülinden geçiş yapılırken insülin seçenekleri bireyselleştirilmelidir. Değişim uygun değilse sahur ile birlikte NPH veya premix insülin dozu; karbonhidrat içeriğine, son insülin dozunun zamanlamasına ve hipoglisemi riskine bağlı olarak \%25 ila $\% 50$ azaltılmalıdır. Uzun etkili bazal insülin analogları içeren tedavi alan (degludec, detemir, glargine, glargine U300) bireylerde hipoglisemi riskini azaltmak için oruç tutarken \%15-30’luk bir doz azalması düşünülmelidir (8). 
- Bolus insülin içeren bir tedavi alan bireylerde, hipoglisemi ve postprandiyal hiperglisemi riskini azaltmak için regüler insüline kıyasla hızlı etkili insülin analoğu (aspart, glulisine, lispro) tercih edilir. Hastalara iftarla normal bolus dozlarını almaları, öğle yemeği bolus dozlarını atlamaları, karbonhidrat alımı ve glukoz ölçümüne bağlı olarak sahur dozlarını \%5-50 arasında azaltmaları tavsiye edilmelidir. İnsülin tedavisi alan bireylerde, hipoglisemi riskini azaltmak amacıyla Ramazan ayında açlık KŞ 5.5 ila $7.5 \mathrm{mmol} / \mathrm{L}$ (100 ila $135 \mathrm{mg} / \mathrm{dL}$ ) arasında olması hedeflenir. Bu konservatif hedeflere ulaşmak için insülin dozu ayarlaması, insülin duyarlılı̆gı ve toplam günlük insülin dozu ile oruç süresi dikkate alınarak bireyselleştirilmelidir. Kompleks insülin tedavisi alan bireyler (özellikle hipoglisemi riski yüksek olanlar) Ramazan ayı öncesi bir diyabet yönetim ekibi tarafından değerlendirilmelidir (8).

Premix insülin kullanımında KŞ’ye göre yaklaşım ve doz değişikliği önerileri Tablo 2'de verilmiştir (8).

\section{b. Tip 1 Diabetes Mellitus}

Ramazan orucu yönetimi, risklerin ciddiyeti nedeniyle tip 1 DM'li bireylerde daha çok zorluk içerir. KŞ düzeylerindeki aşırı sapmalar; şiddetli hipoglisemi, dehidrasyon veya diyabetik ketoasidoz gibi hayatı tehdit eden sonuçlara yol açabilir $(31,32)$. Bu nedenle IDF-DAR kılavuzları, tip 1 DM'li bireyleri yüksek riskli veya çok yüksek riskli olarak sınıflandırmaktadır (6). Yüksek risk altında kabul edilmesine rağmen, tip 1 DM'li birçok birey oruç tutmaktadır. Bununla birlikte, stabil glisemik kontrole sahip olan tip 1 DM'li yetişkin bireylerin, düzenli olarak KŞT ve yakından gözetim ile profesyonel rehberlik altında oruç tutabileceği belirtilmiştir. Glukoz kontrolünün stabilitesi için kriterler arasında; ciddi komplikasyonların olmaması ve Ramazan'dan önceki 3 ay içinde ciddi hipoglisemi veya ketoasidoz ataklarının olmaması yer almaktadır. Metabolik kontrolü zayıf, KŞT’ye uymayan veya hipoglisemi farkındalığı olmayan tip 1 DM'li bireyler oruç tutmaktan vazgeçirilmelidir (3).
Tip 1 DM'li bireylerde yaygın olarak kullanılan insülin tedavileri; günlük çoklu insülin enjeksiyonları (ÇİE), premix insülin ve sürekli subkutan insülin infüzyonudur (SSİI) (32).

SSİ̇, ÇİE ile karşılaştırıldığında daha iyi glisemik kontrol ve daha az hipoglisemik olay ile ilişkilidir. Birleşik Krallık’taki Ulusal Klinik Mükemmellik Enstitüsü (The National Institude for Health and Care Excellence, NICE), ADA ve EASD; tip 1 DM'li bireylerde insülin tedavisi için SSIİ'yi en iyi seçenek olarak önermektedir (14). Bir meta-analizde, SSIII ile tedavi edilen bireylerin, premix insülin veya ÇİE ile tedavi edilenlere kıyasla daha düşük hiperglisemi, ketoz ve oruç bozma oranlarına sahip olduğunu göstermiștir (33). Bunun aksine başka bir meta-analizde, SSIII ile tedavi edilenlerde diğer tedavi yöntemlerine göre hipogliseminin yüksek olduğu gösterilmiştir (32).

Aşağıda IDF-DAR kılavuzlarına göre Ramazan ayında tip 1 DM'li bireylerin kullandığı insülin tedavileri ile ilgili öneriler yer almaktadır;

- Oruç tutma niyetinde olan tip 1 DM'li bireyler için, bireysel riskleri değerlendirmek ve insülin yönetimini optimize etmek için Ramazan'dan 1 ila 3 ay önce tıbbi bir değerlendirme yapılmalıdır (6).

- Kötü kontrollü tip 1 DM'liler (yani Ramazan öncesi A1C seviyeleri > \%9, KŞ’yi düzenli olarak ölçmeyenler ve hipoglisemi farkındalığı olmayanlar) oruç tutmamalıdır (6).

- İnsülin lispro (hızlı etkili bir insülin analoğu), günde iki kez alınan bir orta etkili insülin ile kombinasyon hâlinde kullanıldığında hipogliseminin önlenmesi için regüler insülininden daha üstündür $(6,34)$.

- İnsülin pompası tedavisinin, oruç sırasında hipoglisemi oranlarını azaltmada bazal-bolus enjeksiyon tedavisinden üstün olmadığı ancak daha az glukoz değiş̧enliğine neden olduğu gösterilmiştir (35). Yine de Ramazan ayında yapılan insülin pompası çalışmalarının hiçbirinin randomize olmadığı akılda tutulmalıdır (6).

Tablo 2: Ramazan ayında premix insülin titrasyonu algoritması (8)

\begin{tabular}{ll}
\hline Açlık Kan Şekeri & Önerilen Eylem \\
\hline$>16.6 \mathrm{mmol} / \mathrm{L}(300 \mathrm{mg} / \mathrm{dL})$ & $\begin{array}{l}\text { Oruç hemen bozulmalı } \\
\text { Günlük insülin dozu \%20 arttırılmalı }\end{array}$ \\
\hline$>10 \mathrm{mmol} / \mathrm{L}(180 \mathrm{mg} / \mathrm{dL})$ & Günlük insülin dozu \%10 arttırılmalı \\
\hline $5.5-10 \mathrm{mmol} / \mathrm{L}(100-180 \mathrm{mg} / \mathrm{dL})$ & Değişiklik yapılmasına gerek yok \\
\hline$<3.9 \mathrm{mmol} / \mathrm{L}(70 \mathrm{mg} / \mathrm{dL})$ & $\begin{array}{l}\text { Oruç hemen bozulmalı } \\
\text { Günlük insülin dozu \%20 azaltılmalı }\end{array}$ \\
\hline$<2.8 \mathrm{mmol} / \mathrm{L}(50 \mathrm{mg} / \mathrm{dL})$ & $\begin{array}{l}\text { Oruç hemen bozulmalı } \\
\text { İnsülin durdurulmalı veya günlük insülin dozu \%30-40 oranında azaltılmalı }\end{array}$ \\
\hline
\end{tabular}


- Bolus insülin dozu Ramazan ayında bireysel yeme alışkanlıklarına göre kişiselleştirilmelidir. Oruç sırasında karbonhidrat sayımı veya tahminine dayalı titrasyon teşvik edilmelidir (6).

- Gündüz oruçluyken, özellikle insülin pompasında olmak üzere bazal insülin dozunun \%5-25 arasında azaltılması önerilir. Özellikle yazları uzun oruç süresi göz önüne alındığında, bazal insülin enjeksiyonlarında bireyselleştirilmiş bir azalma olacaktır ve KŞT verilerine dayanarak haftalık olarak yeniden değerlendirme yapılmalıdır (6).

- Bolus insülin olarak regüler insülin kullananlarda, Ramazan'dan 1-3 ay önce hızlı etkili insülin analoğuna geçiş yapılması hipoglisemi oranlarını azaltmaktadır (6).

- Bazal-bolus enjeksiyon tedavisi kullananlar için, Ramazan ayında orta etkili insüline kıyasla bazal analog insülin (detemir, glargin) tercih edilmelidir. Alternatif olarak, hipoglisemi riskini daha da azaltmak ve uzun süreli açlık dönemlerinde kaçırılan insülin dozlarını en aza indirmek için günde bir kez ultra uzun etkili bazal insülin (degludec, glargine U300) kullanılabilir $(6,18)$.

- İnsülin-karbonhidrat oranları ve insülin duyarlık faktörleri stabil tutulmalı ve iyi kontrol edilmeli, oruç sırasında değişmeden kalmalıdır (6).

- Tip 1 DM’li bireyler, diyabetik ketoasidoz taraması için KŞT'de glukoz seviyeleri yükseldiğinde (>14 mmol/L veya $>252 \mathrm{mg} / \mathrm{dL}$ ) kan ketonlarını izlemelidir. Kan ketonlar1 $>0.6 \mathrm{mmol} / \mathrm{L}(<10 \mathrm{mg} / \mathrm{dL})$ olanlar orucu bozmalı, kan ketonlarını düzeltmek için hızlı etkili insülin dozu almalıdır ve Ramazan ayında güvenli bir şekilde oruç tutup tutamayacakları yeniden değerlendirmelidir (6).

\section{c. Glisemik Kontrolün Yönetimi}

Oruç tutan bireylerin 'Cilde bir şey batırmak orucu geçersiz kılar' düşüncesi yaygın olmasına rağmen Müslüman din alimleri glisemik kontrolü sağlamak için uygulanacak işlemin orucu bozmadığ konusunda hemfikirdir $(3,36)$.

DM'de teknolojinin kullanımı giderek artmakta ve ilaçların ayarlanması, optimal KŞ kontrolü ve ögün içeriğinin belirlenmesinde büyük kolaylık sağlamaktadırlar (8). KŞT, DM yönetiminin temelini oluşturur. Ancak, KŞT ile orucun bozulacağı ve bireyin KŞ’yi sık sık kontrol ettiği sırada hipoglisemi ataklarını bulduğu için orucu bozması gerekeceğini düşüncesi takip sıklığını azaltmaktadır. Aslında sık izlem hipoglisemik atakların sıklığını ve şiddetini azaltarak Ramazan ayının güvenle geçmesini sağlamaktadır (3). Yapılan bir çalışmada, DM'li bireylerle Ramazan öncesi ve sırasında sürekli KŞT oruç tutarken kan glukozlarında anlamlı olmayan bir düşüşe ve ayrıca Ramazan sonrası dönemde de hipoglisemik olaylarda anlamlı düzeyde azalmaya neden olduğu saptanmıştır (37).
Tip 1 DM'li bireylerde geriye dönük bir yıl incelendiğinde, hipoglisemi insidansının Ramazan ayından yılın diğer aylarına göre anlamlı derecede daha yüksek olduğu ve Ramazan öncesi sağlanan iyi glisemik kontrolün oruç sırasında glukoz dalgalanmalarını azaltacağı belirtilmiştir (38).

Ramazan ayı gibi kısa bir sürede HbA1c, glisemik kontroldeki değişikliği tam olarak yansıtamadığından, glukoz ölçüm yöntemlerinin (KŞT, sürekli glukoz izlemi, anlık glukoz izlemi) önemi artmaktadır (38).

Ramazan ayında insülin tedavisi alan ve oruç tutan bireylerde, oruç sırasında KŞT sıklığı konusunda eğitim verilmelidir. Semptomatik hipoglisemi veya hiperglisemi dönemlerine ek olarak, tip 1 DM'li bireylere günde en az 5 kez ve tip 2 DM'li bireylere günde 2 ila $5 \mathrm{kez} K S ̧ \mathrm{~T}$ önerilmeli ve ölçüm sıklığı duruma göre kişiselleştirilmelidir (3).

\section{SONUC}

Artan Müslüman nüfusa paralel olarak DM'li bireyler arasinda da Ramazan orucunu tutma oranı artmaktadır. Dolayısıyla sağlık uzmanlarının; DM'li bireylerde orucun risklerini, faydalarını bilmeleri, bu süreçte beslenme, egzersiz ve tedavi yönetiminin gerekleri konusunda kişileri bilgilendirmeleri gerekmektedir. Orucun DM'li bireyler üzerine en büyük riski olan hipoglisemi ve hiperglisemiyi en aza indirmek için oruç tutmadan önce ve oruç sırasında çeşitli önlemler alınmalıdır.

Ramazan öncesi verilecek olan yapılandırılmış eğitimler tedavi sonuçlarının iyileşmesini ve oluşacak komplikasyonlarm önlenmesini sağlayabilir. Komplikasyonu olan ya da komplikasyon gelişme riski yüksek olan DM'li bireyler oruç tutmamalıdır veya orucun bozulmasını gerektiren durumlar hakkında detaylı bir şekilde bilgilendirilmelidir.

İlaç seçimlerine karar verilirken ko-morbiditeler de dahil olmak üzere bireysel faktörler dikkate alınmalıdır. DM’li bireylerde hipoglisemi veya hiperglisemi ataklarına karşı alınabilecek en etkili yöntem, KŞT ile sağlanacak iyi bir glisemik kontrolden geçer. Verilen eğitimlerin sürekliliği ve uzmanlar tarafından standartlaştırılmış olması DM'li bireylerin Ramazan ayında oruç sırasında DM'lerini güvenli bir şekilde yönetmelerine yardımcı olacaktır.

Teșekkür

Yok.

Yazarların Makaleye Katkı Beyanı

Fikir, metodoloji, yazma-orijinal taslak, yazma-gözden geçirme ve düzenleme, kaynaklar, doğrulama: Aslı Onur, Kavramsallaştırma, metodoloji, inceleme ve düzenleme: Zeynep Caferoğlu, Veri iyileştirme, denetim: Nihal Hatipoğlu. 


\section{Çıkar Çatışması}

Yazarların bu yazı için çıkar çatışması bulunmamaktadır.

Finansal Destek

Finansal bir destek yoktur.

\section{Etik Kurul Onayı}

Deneysel ve insan ürünü kullanılmadığından etik kurul oluru gerekmemiştir.

\section{Hakem Değerlendirmesi}

Kör hakemlik sürecinde yayınlanmaya uygun bulunmuş ve kabul edilmiştir.

\section{KAYNAKLAR}

1. Lessan N, Ali T. Energy metabolism and intermittent fasting: The ramadan perspective. Nutrients. 2019;11(5):1192.

2. Bener A, Al-Hamaq AOAA, Öztürk M, Çatan F, Haris PI, Rajput KU, et al. Effect of ramadan fasting on glycemic control and other essential variables in diabetic patients. Ann Afr Med. 2018;17(4):196-202.

3. Bajaj HS, Abouhassan T, Ahsan MR, Arnaout A, Hassanein M, Houlden RL, et al. Diabetes Canada position statement for people with types 1 and 2 diabetes who fast during Ramadan. Can J Diabetes. 2019;43(1):3-12.

4. Grajower MM, Horne BD. Clinical management of intermittent fasting in patients with diabetes mellitus. Nutrients. 2019;11(4):1-11.

5. Salti I, Bénard E, Detournay B, Bianchi-Biscay M, Le Brigand C, Voinet C, et al. A population-based study of diabetes and its characteristics during the fasting month of ramadan in 13 countries: Results of the epidemiology of diabetes and ramadan 1422/2001 (EPIDIAR) study. Diabetes Care. 2004;27(10):2306-2311.

6. Hassanein M, Al-Arouj M, Hamdy O, Bebakar WMW, Jabbar A, Al-Madani A, et al. Diabetes and Ramadan: Practical guidelines. Diabetes Res Clin Pract. 2017;126:303-316.

7. Tan C, Yong AML, Haji Mohamad MA, Abdul Rahman H, Naing L. Fasting in Ramadan of Muslim patients with diabetes Mellitus, and knowledge and practice in relation to diabetes control in Brunei. Diabetes Res Clin Pract. 2018;144:171-176.

8. Ibrahim M, Davies MJ, Ahmad E, Annabi FA, Eckel RH, BaEssa EM, et al. Recommendations for management of diabetes during Ramadan: Update 2020, applying the principles of the ADA/EASD consensus. BMJ Open Diabetes Res Care. 2020;8(1):1-14.

9. Jabbar A, Hassanein M, Beshyah SA, Boye KS, Yu M, Babineaux SM. CREED study: Hypoglycaemia during Ramadan in individuals with Type 2 diabetes mellitus from three continents. Diabetes Res Clin Pract. 2017;132:19-26.

10. Malik U, Mahmood N, Khan KA, Hameed M, Randhawa FA, Salman S, et al. Glycaemic control of type 2 diabetic patients during Ramazan fasting. J Ayub Med Coll Abbottabad. 2017;29(1):102-106.
11. Rashid F, Abdelgadir E. A systematic review on efficacy and safety of the current hypoglycemic agents in patients with diabetes during Ramadan fasting. Diabetes Metab Syndr Clin Res Rev. 2019;13(2):1413-1429.

12. Ahmedani MY, Haque MS, Basit A, Fawwad A, Alvi SFD. Ramadan Prospective Diabetes Study: The role of drug dosage and timing alteration, active glucose monitoring and patient education. Diabet Med. 2012;29(6):709-715.

13. Bravis V, Hui E, Salih S, Mehar S, Hassanein M, Devendra D. Ramadan education and awareness in diabetes (READ) programme for Muslims with type 2 diabetes who fast during Ramadan. Diabet Med. 2010;27(3):327-331.

14. Gad H, Al-Muhannadi H, Purra H, Mussleman P, Malik RA. The effect of Ramadan focused education on patients with type 2 diabetes: A systematic review and meta-analysis. Diabetes Res Clin Pract. 2020;162:108122.

15. Mafauzy M. Repaglinide versus glibenclamide treatment of Type 2 diabetes during Ramadan fasting. Diabetes Res Clin Pract. 2002;58(1):45-53.

16. Brady EM, Davies MJ, Gray LJ, Saeed MA, Smith D, Hanif $\mathrm{W}$, et al. A randomized controlled trial comparing the GLP-1 receptor agonist liraglutide to a sulphonylurea as add on to metformin in patients with established type 2 diabetes during Ramadan: the Treat 4 Ramadan Trial. Diabetes Obes Metab. 2014;16(6):527-536.

17. Azar ST, Echtay A, Wan Bebakar WM, Al Araj S, Berrah A, Omar M, et al. Efficacy and safety of liraglutide compared to sulphonylurea during Ramadan in patients with type 2 diabetes (LIRA-Ramadan): A randomized trial. Diabetes Obes Metab. 2016;18(10):1025-1033.

18. Hassanein M, Buyukbese MA, Malek R, Pilorget V, Naqvi $\mathrm{M}$, Berthou $\mathrm{B}$, et al. Real-world safety and effectiveness of insulin glargine $300 \mathrm{U} / \mathrm{mL}$ in participants with type 2 diabetes who fast during Ramadan: The observational ORION study. Diabetes Res Clin Pract. 2020;166:108189.

19. Josse RG, Chiasson J-L, Ryan EA, Lau DCW, Ross SA, Yale $\mathrm{J}-\mathrm{F}$, et al. Acarbose in the treatment of elderly patients with type 2 diabetes. Diabetes Res Clin Pract. 2003;59(1):37-42.

20. DiNicolantonio JJ, Bhutani J, O’Keefe JH. Acarbose: safe and effective for lowering postprandial hyperglycaemia and improving cardiovascular outcomes. Open Heart. 2015;2(1):e000327.

21. Bodmer M, Meier C, Krähenbühl S, Jick SS, Meier CR. Metformin, sulfonylureas, or other antidiabetes drugs and the risk of lactic acidosis or hypoglycemia: A nested case-control analysis. Diabetes Care. 2008;31(11):2086-2091.

22. Wright AD, Cull CA, Macleod KM, Holman RR, Group U. Hypoglycemia in type 2 diabetic patients randomized to and maintained on monotherapy with diet, sulfonylurea, metformin, or insulin for 6 years from diagnosis: UKPDS73. J Diabetes Complications. 2006;20(6):395-401.

23. Devendra D, Gohel B, Bravis V, Hui E, Salih S, Mehar S, et al. Vildagliptin therapy and hypoglycaemia in Muslim type 2 diabetes patients during Ramadan. Int J Clin Pract. 2009;63(10):1446-1450. 
24. Halimi S, Levy M, Huet D, Quéré S, Dejager S. Experience with vildagliptin in type 2 diabetic patients fasting during Ramadan in France: Insights from the VERDI study. Diabetes Ther. 2013;4(2):385-398.

25. Al Sifri S, Basiounny A, Echtay A, Al Omari M, HarmanBoehm I, Kaddaha G, et al. The incidence of hypoglycaemia in Muslim patients with type 2 diabetes treated with sitagliptin or a sulphonylurea during Ramadan: A randomised trial. Int J Clin Pract. 2011;65(11):1132-1140.

26. Aravind SR, Tayeb K Al, Ismail SB, Shehadeh N, Kaddaha G, Liu R, et al. Hypoglycaemia in sulphonylurea-treated subjects with type 2 diabetes undergoing Ramadan fasting: A five-country observational study. Curr Med Res Opin. 2011;27(6):1237-1242.

27. Wan Seman WJ, Kori N, Rajoo S, Othman H, Wahab NA, Sukor N, et al. Switching from sulphonylurea to a sodiumglucose cotransporter2 inhibitor in the fasting month of Ramadan is associated with a reduction in hypoglycaemia. Diabetes Obes Metab. 2016;18(6): 628-632.

28. Hassanein M, Bashier A, Randeree H, Abouelmagd M, AlBaker W, Afandi B, et al. Use of SGLT2 inhibitors during Ramadan: An expert panel statement. Diabetes Res Clin Pract. 2020;169:108465.

29. Papanas N, Katsiki N, Hatzitolios AI, Maltezos E. Pioglitazone: A valuable component of combination therapy for type 2 diabetes mellitus. Expert Opin Pharmacother. 2011;12(10):1457-1461.

30. Al-Arouj M, Hassoun AAK, Medlej R, Pathan MF, Shaltout I, Chawla MS, et al. The effect of vildagliptin relative to sulphonylureas in Muslim patients with type 2 diabetes fasting during Ramadan: The VIRTUE study. Int J Clin Pract. 2013;67(10):957-963.
31. Abdelgadir EIE, Hafidh K, Basheir AMK, Afandi BO, Alawadi F, et al. Comparison of incidences, hospital stay and precipitating factors of diabetic ketoacidosis in Ramadan and the following month in three major hospitals in United Arab Emirates. A Prospective Observational Study. J Diabetes Metab. 2015;6:514.

32. Loh HH, Lim LL, Loh HS, Yee A. Safety of Ramadan fasting in young patients with type 1 diabetes: A systematic review and meta-analysis. J Diabetes Investig. 2019;10(6):1490-1501.

33. Frier BM. Hypoglycaemia in diabetes mellitus: Epidemiology and clinical implications. Nat Rev Endocrinol.2014;10(12):711722 .

34. Kadiri A, Al-Nakhi A, El-Ghazali S, Jabbar A, Al MA, Akram J, et al. Treatment of type 1 diabetes with insulin lispro during Ramadan. Diabetes Metab. 2001;27(4 Pt 1):482-486.

35. Alamoudi R, Alsubaiee M, Alqarni A, Saleh Y, Aljaser S, Salam A, et al. Comparison of insulin pump therapy and multiple daily injections insulin regimen in patients with type 1 diabetes during Ramadan fasting. Diabetes Technol Ther. 2017;19(6):349-354.

36. Masood SN, Masood Y, Mumtaz SN, Maqsood A, Hakim R, Shaikh Z, et al. Ramadan fasting related awareness, practices and experiences of a representative group of Urban Pakistani Diabetics. Pak J Med Sci. 2012;28: 432-436.

37. Eid YM, Sahmoud SI, Abdelsalam MM, Eichorst B. Empowerment-based diabetes self-management education to maintain glycemic targets during ramadan fasting in people with diabetes who are on conventional insulin: A feasibility study. Diabetes Spectr. 2017;30(1):36-42.

38. Kaplan W, Afandi B. Blood glucose fluctuation during ramadan fasting in adolescents with type 1 diabetes: Findings of continuous glucose monitoring. Diabetes Care. 2015;38(10):e162-163. 